\title{
Smoking in chronic psychiatric illness: is it worth it?
}

\author{
C. McDonald and N. Sheppard
}

\begin{abstract}
The prevalence of smoking is higher among chronic poychiatric patients than the general population, in splite of their lower income. The purpose of this study was to calculate the percentage of income these patients spend on smoking and to cliscuss the relotionship between smoking and chronic poychiatile disorders, in particular schlzophrenia. Ninety-stx smokers were included in the study. The mean percentage expenditure on smoking was $29.4 \%$ of income. We discuss why chronic poychiatic patients smoke so much, why they should not, and what factors may encourage them to quit.
\end{abstract}

The prevalence of tobacco smoking is higher among psychiatric patients than the general population (Hughes et al, 1986). As the price of cigarettes continues to rise and as psychiatric patients move into the community and become eligible for public financial support, the financial implication of maintaining such an expensive habit in such a low income population becomes a cause of concern. The purpose of this study was to calculate what percentage of income chronic psychiatric patients spend on tobacco products. In addition, we discuss why psychiatric patients smoke so much, why they should not, and what factors may encourage them to stop.

\section{The study}

Psychiatric patients were individually interviewed by a psychiatric house officer or psychiatric nurse and a questionnaire completed.

In order to avoid bias, with more heavy smokers being included in the study, we took a distinct population of all patients living in hostels and group homes in the Waterford and Dungarvan areas and interviewed all current smokers. Of 88 patients living in hostels and group homes, 53 were smokers. Thus the prevalence rate was $61 \%$, similar to other prevalence studies on psychiatric patients and well above the national average of 28\% (Doorley, 1994). Fifteen of these patients lived in high support hostels and 38 lived in low support hostels or group homes. All 53 patients were interviewed (Group 1).

To expand the patient sample, we took a further 43 out-patients (Group 2). Nursing staff were asked to list patients who had "chronic schizophrenia', and who were smokers, at a number of out-patient sessions. A few of these patients were randomly selected and interviewed at each session. Thus the total patient sample was 96.

The questionnaire assessed demographic details, average number of cigarettes smoked per day, weekly income, sources of income and the amount of money spent on cigarettes per week. The source and amount of income was crosschecked with nursing records to ensure validity when possible, mostly with those living in hostels or attending day-centres.

The amount of money spent on cigarettes per week was expressed as a percentage of total weekly income for each patient and the mean percentage of weekly income spent on cigarettes was calculated. Two sample unpaired student $t$ tests were applied to the demographic details and percentage of income spent on cigarettes to see if any significant differences existed between the two groups.

\section{Findings}

Of the 96 smokers (Groups 1 and 2), 78 (81\%) were men and $18(19 \%)$ were women. There was no difference in gender distribution between the two groups. The higher prevalence of smoking among male psychiatric patients has been noted previously (Goff et al, 1992). The mean age was 51 (range 22-78). There was no significant difference $(t=0.84, P=0.40)$ between the two groups when age data were analysed using a two-sample unpaired student $t$-test.

Ninety-two patients received social security benefits (public financial support), either Disabled Person's Maintenance Allowance ( $\$ 61$ p.w.), Invalidity Pension ( $\$ 62.60$ p.w.), Old Age Pension (£71 p.w.) or Widow's Pension ( $\$ 64.50$ p.w.). Of the remaining four, one recetved a pension $(£ 160$ p.w.), two received income from a working spouse ( $£ 67.50$ p.w. and $£ 100$ p.w.) and one had a personal income of $£ 73$ p.w.

In addition to income from social security benefits, 30 patients recetved some form of additional income, mostly from the occupational therapy unit or pocket money from relatives 
Table 1. Mean expenditure on smoking per week

\begin{tabular}{llllll}
\hline & $\begin{array}{l}\text { Gender } \\
\text { M:F }\end{array}$ & Mean age (s.d.) & $\begin{array}{l}\text { Mean income } \\
\text { per week (s.d.) }\end{array}$ & $\begin{array}{l}\text { Mean no. of } \\
\text { cigs/doy (s.d.) }\end{array}$ & $\begin{array}{l}\text { \% exp. } \\
\text { on clos }\end{array}$ \\
\hline Group 1 & $43: 10$ & $52.1(12.0)$ & $568.03(\$ 15.20)$ & $22.6(9.6)$ & $30.0 \%$ \\
Group 2 & $35: 8$ & $50.1(12.0)$ & $569.46(\$ 14.67)$ & $21.1(9.0)$ & $28.6 \%$ \\
Total & $78: 18$ & $51.2(12.0)$ & $568.64(\$ 14.86)$ & $22.0(9.3)$ & $29.4 \%$ \\
\hline
\end{tabular}

Group 1=Patients IVing in hostels and group homes

Group 2=Patients attending out-patient services

(range $£ 3-£ 60$ p.w.). Eighty-seven of the patients subsisted on a weekly income of less than $£ 75$.

The average weekly income per person was \$68.64 (range £61-£160) and the average number of cigarettes smoked per day was 22 (range 3-60). Eight patients smoked rolled cigarettes. One patient smoked a pipe.

The mean percentage expenditure on smoking per week was $29.4 \%$. A two-sample unpaired student $t$-test analysis was used to compare mean percentage expenditure on cigarettes. No significant difference between the two groups was found ( $t=0.52, P=0.61$; see Table 1$)$.

Patients living in low support hostels and group homes $(n=38)$ pay a flat weekly rent for accommodation, food and bills (£27.50). If this is subtracted from their weekly income and the proportion spent on smoking calculated, the percentage of (disposable) income spent on smoking by these patients is $51.9 \%$.

\section{Comment}

Why do chronic psychiatric patients smoke so much?

Several factors contribute to the high prevalence of smoking in this patient group. Patients are more often bored and use smoking as a behavioural filler. It can enhance concentration and reduce discomfort from hyperarousal. These patients may have higher levels of impulsivity or other personality traits associated with smoking and are more likely to become dependent on drugs. The higher prevalence cannot be attributed to patterns of age, gender, marital status, socioeconomic status, alcohol use, coffee use or institutionalisation (Hughes et al, 1986).

There is a particularly high rate of smoking among patients with schizophrenia and further reasons for this have been suggested: smoking may decrease neuroleptic side-effects through a pharmacokinetic interaction, as there is increased clearance of these drugs associated with cigarette smoking. Smokers have lower levels of chlorpromazine-induced sedation, attributed to lower chlorpromazine plasma concentrations (Goff et al, 1992).

Smoking may have beneficial effects on the negative symptoms of schizophrenia through modulation of dopamine activity. Nicotine increases the release of dopamine from the nucleus accumbens by shifting the firing of ventral tegmental cells into burst firing rather than a regular pattern. The release of dopamine from the nucleus accumbens has been associated with reward mechanisms in the brain. The normal physiological mechanism for shifting ventral tegmental dopamine cells into burst firing is by excitatory fibres from the prefrontal cortex. The prefrontal cortex may be hypoactive in schizophrenia and this hypofrontal syndrome has been associated with the negattve symptoms of schizophrenia. The hypothesis, therefore, is that the apathy and lack of mottivation of patients with schizophrenia may be related to diminished reward system activity which the patients are attempting to stimulate with nicotine (Glassman, 1993).

Cigarette smoking may reduce the Parkinsonian side-effects of neuroleptic medication. In the general population, there is an association between smoking and a reduction in the incidence of idiopathic Parkinson's disease. In studies on psychiatric patients, smokers have displayed significantly less neuroleptic-induced Parkinsonism, in spite of receiving higher doses of neuroleptic medication. Patients with schizophrenia may also be encouraged to smoke more in order to medicate underlying affective symptoms of their illness as nicotine has a mood elevating effect (Goff et al, 1992).

Why should chronic psychiatric patients not smoke so much?

The heavy smoking habits of patients with chronic schizophrenia may be one of the few pleasures left for them, so why should they stop? Smoking in the general population causes increased mortality from several illnesses, especially cancer and cardiovascular disease. Most studies have found a higher rate of cardiovascular disease, infectious disease and pulmonary disease among patients with schizophrenia compared with the general population (Tsuang et al, 1983).

However, there are suggestions of a reduced mortality from lung cancer. Most studies have 
failed to meet methodological standards necessary to draw conclusive evidence, but Gulbinat et al (1992) recently reported results from record linkage studies and found lower rates of lung cancer among patients with schizophrenia in Denmark. A reduced incidence of lung cancer is all the more striking since these patients usually have a more intensive exposure to the principal risk factor for lung cancer.

Apart from health risks to the patient, smoking poses significant health risks to others in their immediate environment because of secondary smoke inhalation. Tobacco smoke can cause lung cancer in non-smokers and may be a risk factor for cardiovascular disease. Therefore other nonsmokers sharing the patient's accommodation or care facility, including mental health care providers, are at increased risk of physical morbidity.

Another negative aspect of smoking is the damage to property caused by cigarette burns to furniture and carpets and the discoloration of paintwork and wallpaper by smoke, leading to higher maintenance costs. There is also a higher risk of death or injury due to accidental fire setting.

Since many chronic psychiatric patients cannot work and must subsist on limited financial resources, funding this expensive habit represents a significant drain on income, as shown by this paper.

\section{How to reduce the prevalence of smoking}

Psychiatric patients are a difficult population in which to encourage smoking cessation. They have less desire to stop smoking, are less motivated and often have impaired cognitive functioning, which may preclude following detailed instructions regarding techniques such as selfmonitoring and appropriate use of nicotine gum (Hartman et al, 1991). Not only is smoking cessation more difficult for them, but successful cessation carries with it the risk of exacerbating their psychopathology. For patients with an affective component to their illness, abstinence may trigger depressive symptoms (and subsequent cessation failure) and in certain smokers can precipitate major depression (Glassman, 1993).

Transdermal nicotine patches have been shown to reduce the quantity of cigarettes smoked among psychiatric patients who were not even trying to stop smoking (Harman et al, 1991). There is also some anecdotal evidence that nicotine chewing gum may assist psychiatric patients to quit (Leong \& Horn, 1989).

The price of cigarettes has a significant effect on smoking prevalence in the general population in socioeconomic group $\mathrm{V}$, for whom prevalence is highest (Townsend et al, 1994). In this group, which is the least responstve to health publicity measures, increases in cigarette prices seem to have had a strong impact on reducing smoking levels. Economic factors rather than concern about adverse health effects also appear to contribute to the decision to terminate smoking by psychiatric patients (Leong \& Horn, 1989). Perhaps this money would be better spent on clothing, personal possessions or leisure activities. Patients deserve encouragement and assistance if they would like to give up this very expensive habit.

\section{Acknowledgements}

The authors wish to express their thanks to Dr Marie Leahy, Mr Terry Hayes, CPN, and the nursing staff of Glendower House and Dungarvan day centre for assistance in the data collection and to Mr Tony Kinsella for statistical advice.

\section{References}

DOORLEY, P. (1994) Prospects for achieving the national target on smoking prevalence by the year 2000. Irish Medical Journal, 87, 158.

GLASSMAN, A. H. (1993) Cigarette smoking: implications for psychiatric illness. American Journal of Psychiatry, 150. 546-553.

GofF, D. C., Henderson, D. C. \& AMico, E. (1992) Cigarette smoking in schizophrenia: relationship to psychopathology and medication side effects. American Journal of Psychiatry, 149, 1189-1194.

GulBINAT, W., DuPONT, A., JABLENSKY, A., et al (1992) Cancer incidence of schizophrenic patients - results of record linkage studies in three countries. British Joumal of Psychiatry, 161, 75-85.

Hartman, N., LeONG, G. B., GlynN, S. M., et al (1991) Transdermal nicotine and smoking behaviour in psychiatric patients. American Journal of Psychiatry, 148, 374-375.

HughES, J. R., HATSUKAMI, D. K., MrTCHELL, J. F., et al (1986) Prevalence of smoking among psychlatric outpatients. American Joumal of Psychiatry, 143. 993-997.

LEONG, G. B. \& HORN, M. (1989) Economic mottiation for smoking cessation in chronic psychiatric patients. Acta Psychiatrica Scandinavica, 80, 657-658.

TOWNSEND, J.. RODERICK, P. \& COOPER, J. (1994) Cigarette smoking by socioeconomic group, sex and age: effects of price, income and health publicity. British Medical Journal, s09, 923-927.

TSuANG, M. T., Perkins, K. \& Simpson, J. C. (1983) Physical diseases in schizophrenia and affective disorder. Journal of Clinical Psychiatry, 44, 42-46.

*Colm McDonald, Registrar, St. John of God Hospital, Stillorgan, Co. Dublin; and Noel Sheppard, Consultant Psychiatrist, Waterford Regional Hospital, Waterford

*Correspondence 